\title{
An Introductory Design Project Case Study: Cardboard Beds for Emergency/Refugee Situations
}

\author{
Sean Maw \\ Mount Royal University, Calgary, Alberta, Canada \\ seanmaw@shaw.ca
}

\begin{abstract}
In the Fall of 2013, first-year Mount Royal University engineering design students completed a 5week long team-based project with the objective of producing a cardboard bed for emergency/refugee situations. The project was a success and this paper details how it was run, what lessons were learned, and the nature of the outcomes. For those considering a similar type of project in the future, resources and client groups are described. Ultimately, the student groups were able to design a variety of cardboard beds that supported at least one adult, comfortably. Variations included beds for African cholera outbreaks, Syrian and African refugee camps, and Canadian emergency shelters.
\end{abstract}

Keywords: design, cardboard, refugee, humanitarian, firstyear, engineering

\section{INTRODUCTION}

In first-year engineering design courses, a perennial challenge is the determination of design project topics. At Mount Royal University, in the Fall of 2013, an additional challenge was the imminent closing of the program and the lack of funds and shop access for the design classes. A project was sought that was feasible, fun, interesting, and meaningful. As a material constraint, stock cardboard was chosen since it is inexpensive, recyclable, easy to work with, and readily available. Also, there isn't a steep learning curve associated with its use, and it can be constructed into many different forms.

\section{PROJECT DESIGN TASK}

In refugee camps around the world, food, water and shelter are the top three concerns. Beyond those needs, refugees often end up in camps for long periods of time. Comfort then becomes relevant. The instructor for this course therefore tasked the students with designing an inexpensive cardboard bed for use in emergency/refugee situations. Student knowledge of basic statics and the accessibility of cardboard construction techniques made this a tractable task in the short time available. In groups of 3-5, students had 5 weeks in which to design a bed, prototype it (full scale), and then present it in an oral presentation and in a recommendation report. Students had one $3 \mathrm{hr}$ design lab per week, which usually included a lecture component tied to a text [1], a directed activity component, and undirected project work. Students also attended $1.5 \mathrm{hrs} /$ week of drawing and $1.5 \mathrm{hrs} /$ week of technical writing instruction. In all, the course consisted of two sections of 25 students. For this Build-a-Bed project, students were evaluated through a presentation, a prototype demo, a recommendation report, a log, a feasible solutions assignment, and a self-reflection essay.

\section{DISCUSSION}

The designs produced by the students were all successful such that they all supported at least one adult, and were relatively comfortable. The solution space was varied and rich, drawing upon different extents of portability, ease and speed of assembly, cost, strength, comfort, size, multi-functionality, accessorization, and cardboard types. Some groups developed their design very quickly, while others evolved their designs over the full project period as they considered design criteria based on research, and optimization based on prototyping.

\section{CONCLUSIONS AND FUTURE WORK}

The Build-a-Bed project engaged most of the students. They interacted with potentially real clients such as the Calgary Drop-in Center, the City of Calgary, the UNHCR, and Doctors without Borders (MSF). They produced designs that were very functional. Given the logistical advantages of working with cardboard, further projects of this type will be tried by this author in the future, at the University of Saskatchewan.

\section{Acknowledgements}

The author thanks all of the students in the two ENGR 1271 classes, as well as Instabox Calgary for providing the cardboard used in the project.

\section{References}

[1] McCahan, Anderson, Kortschot, Weiss and Woodhouse, Designing Engineers: An Introductory Text, Mount Royal University ENGR 1271 Edition, John Wiley \& Sons, 2013 